\title{
Muscle Physiology, Contractile
}

National Cancer Institute

\section{Source}

National Cancer Institute. Muscle Physiology, Contractile. NCI Thesaurus. Code C18889.

The physiology of muscle contraction 